\title{
Analisis Rasio Pada Akun Youtube Untuk Penelitian Kualitatif Menggunakan Metode Ekploratif
}

\author{
I Putu Hendika Permana \\ Teknik Informatika, STMIK STIKOM Indonesia \\ Jl. Tukad Pakerisan No.97, Panjer, Denpasar Selatan, Bali, Indonesia \\ hendika@stiki-indonesia.ac.id
}

\begin{abstract}
Information and communication technology is currently developing rapidly, this has made more and more types of social media applications appear with different features and functions. One of the most frequently used and influential social media applications is YouTube. This research was conducted with the aim of finding the ratios contained in the YouTube account. These ratios will later be used to measure the performance of an account mathematically. This research was conducted using an exploratory method to find the variables contained in the YouTube account. These variables will be compared and juxtaposed to test their relevance so that they become the relevant ratios. The relevant ratio will be used to assess the performance of each account on YouTube social media. The results of this YouTube social media research show that there are 6 variables, these variables are posts, subscribers, likes, dislikes, viewers, comments. The six variables will be compared and juxtaposed to find 10 relevant ratios. The benefit that can be taken from this research is that in the future it can easily assess, measure and compare the credibility of each YouTube account using the 10 ratios that have been found.
\end{abstract}

Keywords : credibility youtube account, social media, social media account, youtube chanel, youtube ratios.

\begin{abstract}
Teknologi informasi dan komunikasi saat ini telah berkembang dengan pesat, hal ini membuat semakin banyak jenis aplikasi sosial media yang muncul dengan fitur dan fungsi yang berbeda-beda. Salah satu aplikasi sosial media yang sering digunakan dan memiliki pengaruh besar adalah YouTube. Penelitian ini dilakukan dengan tujuan untuk menemukan rasio-rasio yang terdapat pada akun YouTube. Rasio-rasio ini yang nantinya akan digunakan untuk mengukur performa sebuah akun secara matematis. Penelitian ini dilakukan dengan menggunakan metode ekploratif untuk menemukan variabel-variabel yang terdapat pada akun YouTube. Variabel tersebut yang nantinya akan dibandingkan dan disandingkan untuk diuji relevansinya sehingga menjadi rasio yang relevan. Rasio yang relevan akan digunakan untuk menilai performa setiap akun yang ada pada sosial media YouTube. Hasil dari penelitian sosial media youtube ini menunjukan bahwa terdapat 6 variabel, variabel tersebut diantaranya yaitu post, subscriber, likes, dislikes, viewers, comments. Keenam variabel tersebut yang nantinya akan dibandingkan dan disandingkan sehingga menemukan 10 rasio yang relevan. Manfaat yang dapat diambil dari penelitian ini yaitu kedepannya dapat menilai, mengukur serta membandingkan kredebilitas dari setiap akun youtube dengan mudah menggunakan 10 rasio yang telah ditemukan.
\end{abstract}

Kata Kunci : akun media sosial, akun youtube, analisis rasio youtube, kredibilitas akun youtube, media sosial

\section{Pendahuluan}

Teknologi informasi dan komunikasi yang telah berkembang pesat mampu menghantarkan manusia untuk menciptakan bentuk baru cara berkomunikasi dan berinteraksi melalui media sosial. Informasi merupakan kumpulan data yang saling terkait dan telah diproses secara kompleks. Data-data yang tercatat dan saling terkait dikumpulkan, diolah atau diproses sehingga menghasilkan informasi yang tepat dan akurat. Komunikasi merupakan suatu proses penyampaian informasi berupa pesan, ide atau gagasan dari satu pihak kepada pihak lain agar saling mempengaruhi di antara keduanya. Teknologi komunikasi dan informasi merupakan aplikasi pengetahuan dan keterampilan yang digunakan manusia dalam mengalirkan informasi atau pesan dengan tujuan untuk membantu menyelesaikan permasalahan manusia agar tercapai tujuan komunikasi [1]. 
Kemajuan teknologi informasi menjadikan manusia dalam berhubungan dengan pihak lain seakan tidak lagi dibatasi oleh ruang dan waktu. Kapanpun dan dimanapun manusia dengan perangkat teknologi tersebut bisa menjalin hubungan, mendapatkan informasi dan menyebarkan informasi kepada orang lain [2]. Semakin berkembangnya kecanggihan teknologi informasi dan komunikasi menyebabkan terjadinya perubahan budaya masyarakat sehari-hari, perkembangan tersebut tidak terlepas dari penggunaan media bagi kegiatan manusia dalam bidang ekonomi, sosial, politik dan budaya. Media sosial sangat berpengaruh pada kehidupan berinteraksi saat ini, sehingga aplikasi media sosial saat ini ada berbagai macan dengan fungsi dan fitur yang berbeda-beda. Aplikasi sosial media yang sering digunakan adalah Twitter, Instagram, YouTube, WhatsApp, Telegram dan lain sebagainya. Salah satu aplikasi sosial media yang paling banyak memiliki peminat yaitu YouTube.

YouTube merupakan salah satu situs website yang menggunakan internet untuk menjalankan fiturnya, dimana dengan YouTube, seorang pengguna dapat memposting atau menampilkan video maupun animasi agar dapat dilihat dan dinikmati banyak orang [3]. YouTube adalah salah satu layanan dari Google yang memfasilitasi penggunanya untuk memposting video dan bisa diakses oleh pengguna lain dari seluruh dunia secara gratis [4]. Bisa dikatakan YouTube adalah database video yang paling popular di dunia internet, atau bahkan mungkin yang paling lengkap dan variatif. YouTube merupakan situs yang berfungsi untuk menonton kumpulan video yang diunggah dari seluruh dunia dan dapat ditonton dimana saja asalkan kita terhubung dengan internet [5]. Karakteristik dari aplikasi sosial media YouTube adalah seseorang yang telah memiliki akun YouTube atau telah memiliki Channel sendiri dapat memposting konten berupa video yang telah dibuat. Pengguna YouTube lainnya dapat melihat video, memberikan likes serta komentar pada sebuat postingan video.

Aplikasi sosial media YouTube banyak dimanfaatkan oleh para creator untuk memposting konten berupa video yang mereka buat. YouTube juga dapat digunakan sebagai lapak mempromosikan sebuah produk, memposting film, dan lain sebagainya. Kelebihan dan kekurangan yang ada pada aplikasi sosial media YouTube. Kelebihan dari YouTube yaitu bisa melihat dan mengupload video, mendownload setiap video, dapat belajar streaming banyak video bermanfaat dan dapat memilih kualitas video yang akan di tonton. Sedangkan kelemahan dari YouTube adalah bisa disalahgunakan penggunanya, banyak informasi yang menyesatkan, banyak negara yang memblokir YouTube karena memberikan konten yang terlalu bebas seperti video pornografi dan video tidak berguna lainnya. Sehingga dari kelemahan ini diharapkan agar pengguna YouTube lebih cerdas lagi dalam memilih konten video yang akan ditonton [6].

Saat ini aplikasi sosial media YouTube sudah mencapai 2 miliar pengguna aktif. Maraknya penggunaan aplikasi ini membuat para peneliti untuk melakukan penelitian terhadap aplikasi YouTube. Sejauh ini para peneliti sudah ada yang melakukan penelitian pada aplikasi YouTube contohnya seperti penelitian pemanfaatan YouTube sebagai media ajar, pengembangan video blog pada YouTube, pengaruh Vlogger terhadap suatu produk yang dipromosikan dan lain sebagainya. Dari beberapa penelitian yang telah dilakukan belum ada peneliti yang melakukan penelitian untuk mencari rasio-rasio yang terdapat pada akun YouTube. Tujuan dari penelitian ini adalah untuk menemukan rasio-rasio yang terdapat pada YouTube yang kemudian setiap variabel dilakukan perbandingan sehingga menjadi rasio yang relevan. Rasio-rasio ini yang nantinya akan digunakan untuk menilai performa dan kredibilitas yang ada pada sebuah akun YouTube. Penelitian ini menggunakan metode penelitian eksploratif, karena pada dasarnya penelitian eksploratif digunakan untuk merumuskan masalah secara lebih terperinci atau menggambarkan hipotesis bukan menguji hipotesis [7].

Kredibilitas dari sebuah akun sangat penting karena berpengaruh terhadap akursi dan objektifitas berita yang disampaikan kepada publik. Kredibilitas dibentuk ketika seseorang yang mengelola akun YouTube tersebut memiliki sumber pengetahuan yang cukup, keterampilan, dan kepercayaan diri sehingga menghasilkan sebuah konten yang memiliki performa yang baik [8]. Kredibilitas sebuah akun dapat diukur dari performa akun yang harus diukur secara sistematis. Dalam mengukur performa dari sebuah akun diperlukan skala pengukuran yang akan tertuang kedalam rasio-rasio. Ada berbagai macam skala pengukuran, diantaranya yaitu : skala nominal, skala ordinal, skala interval, dan skala rasio. Skala pengukuran tersebut yang akan menimbulkan data berupa rasio [9]. Akun YouTube yang dapat dianalisis untuk menentukan kredibilitas, harus memenuhi syarat setting pada pengaturan akun YouTube. Persyaratan tersebut diantaranya yaitu, akun YouTube merupakan akun yang bersifat publik, video yang diposting tidak dikunci (privacy), kolom komentar tidak di non-aktifkan (disable) 


\section{Metodologi}

Penelitian ini menggunakan metode tipe eksploratif yang akan meneliti seluruh kategori pengguna sosial media YouTube dengan tujuan untuk memperdalam pengetahuan dan mencari ide-ide baru mengenai suatu gejala tertentu, menggambarkan fenomena sosial, dan menjelaskan bagaimana terjadinya suatu fenomena sosial. Penelitian ini dapat dijadikan sebagai acuan penelitian kuantitatif sehingga variabel yang akan dianalisis adalah suatu objek yang memiliki nilai berupa angka sehingga dapat terhitung dalam proses menjadikan atau memformulasikan sebagai rasio. Penelitian ini menggunakan variabel-variabel yang terdapat pada akun sosial media YouTube sebagai objek penelitian sehingga mampu menghasilkan rasio yang relevan. Variabel dapat didefinisikan sebagai atribut atau objek yang mempunyai variasi antara satu dengan yang lainnya. Atribut yang dimaksud contohnya seperti skala, ukuran, rasio, ordinal dan nominal [10]. Berikut merupakan Langkah-langkah menemukan variabel pada akun sosial media YouTube.

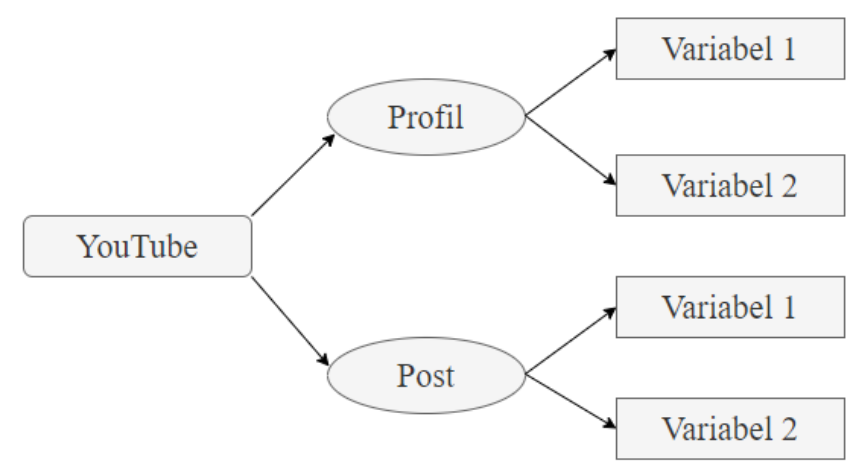

Gambar 1. Menemukan Variabel Pada Akun YouTube

Berikut merupakain uraian langkah-langkah menemukan variabel pada akun YouTube :

Data penelitian ini diperoleh dengan cara menganalisis akun yang ada pada YouTube. Setiap akun yang ada pada YouTube memiliki tampilan halaman yang menunjukan profil serta postingan video yang di upload. Dari tampilan akun dapat di temukan beberapa variabel seperti jumlah postingan dan jumlah subscriber, sedangkan pada tampilan video atau konten yang di upload dapat di temukan beberapa variabel seperti jumlah likes, dislikes, viewers, dan comment. Dimana variabel-variabel yang terdapat pada YouTube tersebut yang nantinya akan dibandingkan dan diuji relevansinya sehingga menemukan sebuah rasio yang relevan.

Rasio merupakan perbandingan satu angka dengan angka yang lain yang membentuk suatu hubungan. Rasio juga merupakan suatu angka digambarkan dalam perbandingan suatu pola dengan pola lainnya serta dinyatakan dalam persentase [11]. Pada penelitian artikel "Prediksi Video Performance Akun YouTube Buzzfeed" menggunakan metode penelitian Nä̈ve Bayes untuk mengetahui bagaimana perkembangan akun pada media sosial YouTube kedepannya dan memprediksi performa dari video-video yang di unggah [12]. Penelitian sebelumnya hanya membahas dan fokus kepada satu akun YouTube saja, dan tidak membahas bagaimana rasio-rasio yang dimiliki dari akun YouTube tersebut. Sehingga pada hasil penelitian dari artikel sebelumnya belum dapat menjawab dan menjelaskan secara detail mengenai performa serta kredibilitas dari masing-masing akun YouTube dan tidak dapat menjelaskan bagaimana rasio yang dimiliki pada sebuah akun media sosial YouTube. Pengumpulan data pada penelitian sebelumnya membutuhkan waktu yang cukup lama yaitu 1 tahun agar dapat menilai performa videovideo yang telah di unggah pada media sosial YouTube. Di karenakan hal tersebut, peneliti mencari dan membuat cara lain untuk dapat menilai performa dan mengukur kredibilitas dari akun media sosial YouTube. Cara yang digunakan pada penelitian ini cukup mudah dan tidak membutuhkan waktu yang lama untuk menemukan sebuah rasio yang relevan. Metode yang digunakan pada penelitian ini adalah metode penelitian tipe eksploratif. Langkah-langkah yang dilakukan pada penelitian tipe eksploratif ini yaitu, dalam menentukan sebuah rasio dibutuhkan minimal 2 variabel yang dibandingkan sehingga menghasilkan sebuah nilai yang hasil akhirnya dinyatakan dalam sebuah persentase. Dari seluruh variabel 
yang ditentukan akan dibandingkan dengan seluruh variabel yang ditemukan lalu diuji relevansinya sehingga dapat ditentukan apakah perbandingan antara kedua variabel dapat dikategorikan sebagai rasio.

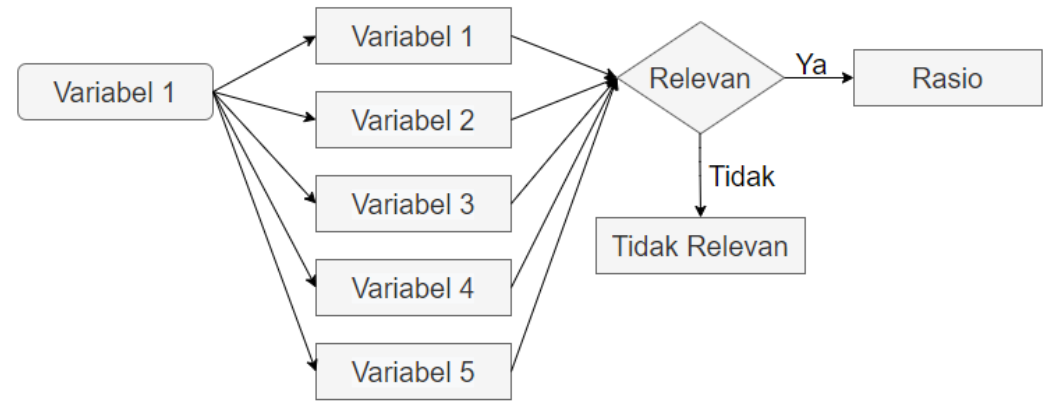

Gambar 2. Relevansi Variabel Terhadap Rasio

Pada gambar relevansi variabel terhadap rasio menunjukan variabel 1 yang dibandingkan dengan seluruh variabel lainnya, sehingga menemukan 2 variabel yang relevan untuk dijadikan rasio. Setelah variabel satu selesai di analisa, dilanjutkan dengan variabel kedua, variabel ketiga dan variabel-variabel yang lainnya. Berikut merupakan contoh studi kasus perbandingan antara variabel yang terdapat pada akun sosial media YouTube :

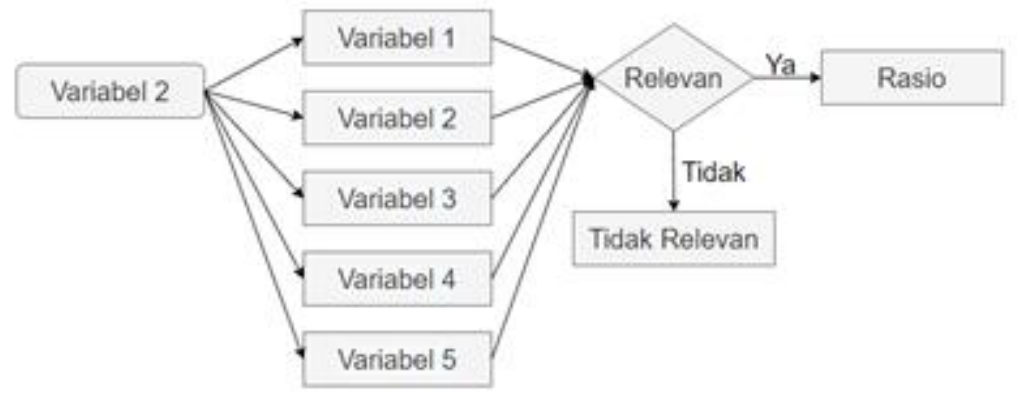

Gambar 3. Contoh Perbandingan Variabel Pada Akun YouTube

Pada gambar contoh perbandingan variabel pada akun YouTube, menunjukan bahwa variabel post dibandingkan atau disandingkan dengan keenam variabel yang lainnya. Hasil dari perbandingan antar variabel menunjukan bahwa variabel post yang dibandingkan dengan variabel post mendapatkan hasil yang tidak relevan. Sedangkan hasil perbandingan pada variabel post dengan variabel subscriber mendapatkan hasil yang relevan, sehingga dapat dijadikan sebuah rasio.

Relevansi rasio ditunjukan dengan menganalisa pengaruh rasio tersebut terhadap penilaian akun YouTube yang di analisa. Rasio termasuk dalam katagori tidak relevan jika perbandingan antar 2 variabel terdapat kondisi sebagai berikut :

1. Perbandingan antar variabel yang sama.

2. Variabel pertama cenderung memiliki nilai yang lebih besar dibandingkan dengan variabel kedua.

3. Kedua variabel tidak dipengaruhi atau ditentukan oleh publik.

4. Kedua variabel tidak pantas atau tidak tepat untuk dibandingkan. 


\section{Hasil dan Pembahasan}

YouTube adalah situs video online dan kegunaan utama dari situs ini adalah sebagai media untuk mencari, melihat, dan berbagi video yang asli ke dan dari segala penjuru dunia melalui situs web. Karakteristik dari YouTube adalah para pengguna dapat mengakses YouTube tanpa batasan waktu dan jumlah data untuk mengunggah video kedalam situs ini. Pengguna dapat mengedit video langsung pada sosial media YouTube karena disediakan alat editing sederhana dengan fitur memotong video, memfilter warna atau juga menambahkan efek transisi.

Dengan melakukan penelitian pada akun sosial media YouTube ditemukan beberapa variabel yang ada, variabel-variabel tersebut diantaranya :

Profile :

- Post

- Subscriber

Post :

- Likes

- Dislikes

- Viewers

- Comments

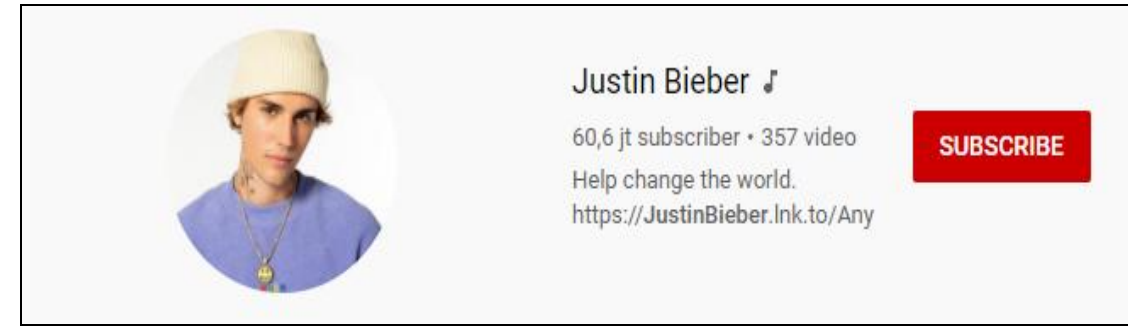

Gambar 4. Variabel Subscriber \& Post [13]

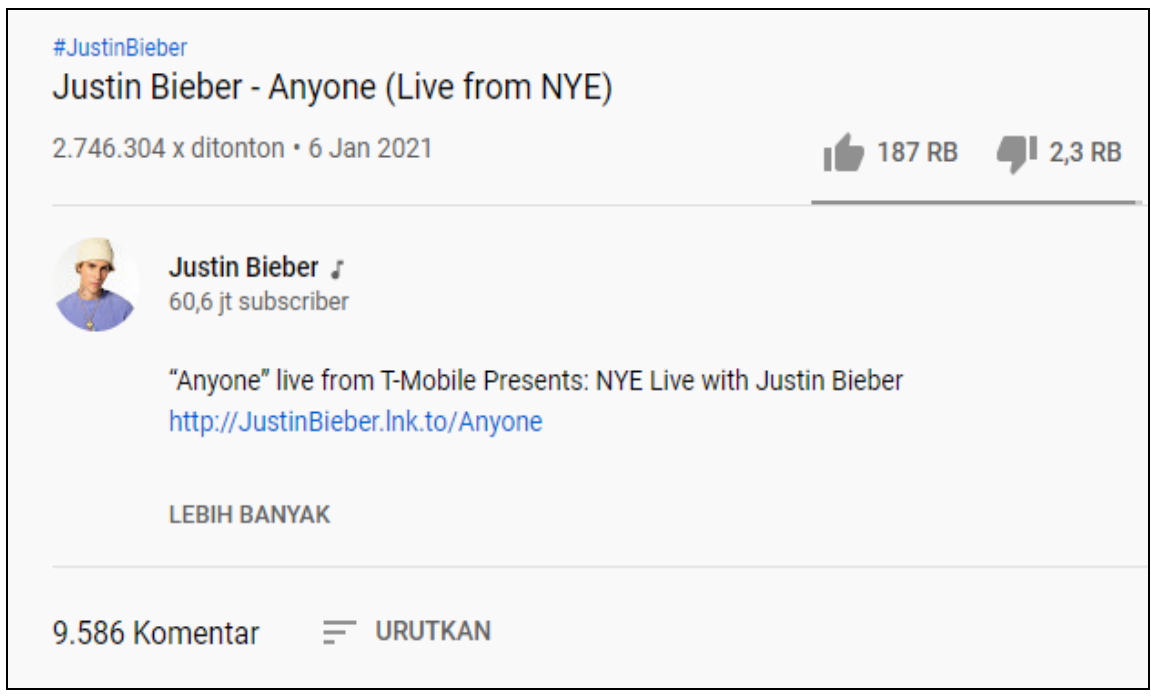

Gambar 5. Variabel Likes, Dislikes, Views, Comments [14]

Terdapat 6 variabel yang akan melalui proses analisis berikutnya yaitu perbandingan antar variabel dan pengujian relevansi antar dua perbandingan variabel. Adapun ke enam variabel tersebut adalah :

1. Post

2. Subscriber

3. Likes 

4. Dislikes
5. Viewers
6. Comments

Tabel 1. Perbandingan Antar Variabel Serta Analisis Relevansi Perbandingan Antar Variabel

\begin{tabular}{|c|c|c|c|}
\hline Variabel 1 & Variabel 2 & Relevansi & Alasan \\
\hline Post & Post & Tidak Relevan & Kedua variabel sama \\
\hline Post & Subscriber & Relevan & \\
\hline Post & Likes & Tidak Relevan & $\begin{array}{l}\text { Jumlah post tidak berpengaruh pada interaksi setiap } \\
\text { postingan }\end{array}$ \\
\hline Post & Dislikes & Tidak Relevan & $\begin{array}{l}\text { Jumlah post tidak berpengaruh pada interaksi setiap } \\
\text { postingan }\end{array}$ \\
\hline Post & Viewers & Tidak Relevan & $\begin{array}{l}\text { Jumlah post tidak berpengaruh pada interaksi setiap } \\
\text { postingan }\end{array}$ \\
\hline Post & Comments & Tidak Relevan & $\begin{array}{l}\text { Jumlah post tidak berpengaruh pada interaksi setiap } \\
\text { postingan }\end{array}$ \\
\hline Subscriber & Post & Tidak Relevan & Jumlah variabel 1 cenderung lebih besar dari variabel 2 \\
\hline Subscriber & Subscriber & Tidak Relevan & Kedua variabel sama \\
\hline Subscriber & Likes & Tidak Relevan & Jumlah variabel 1 cenderung lebih besar dari variabel 2 \\
\hline Subscriber & Dislikes & Tidak Relevan & Jumlah variabel 1 cenderung lebih besar dari variabel 2 \\
\hline Subscriber & Viewers & Tidak Relevan & Jumlah variabel 1 cenderung lebih besar dari variabel 2 \\
\hline Subscriber & Comments & Tidak Relevan & Jumlah variabel 1 cenderung lebih besar dari variabel 2 \\
\hline Likes & Post & Tidak Relevan & $\begin{array}{l}\text { Jumlah post tidak berpengaruh pada interaksi setiap } \\
\text { postingan }\end{array}$ \\
\hline Likes & Subscriber & Relevan & \\
\hline Likes & Likes & Tidak Relevan & Kedua variabel sama \\
\hline Likes & Dislikes & Tidak relevan & Jumlah variabel 1 cenderung lebih besar dari variabel 2 \\
\hline Likes & Viewers & Relevan & \\
\hline Likes & Comments & Tidak Relevan & Jumlah variabel 1 cenderung lebih besar dari variabel 2 \\
\hline Dislikes & Post & Tidak Relevan & $\begin{array}{l}\text { Jumlah post tidak berpengaruh pada interaksi setiap } \\
\text { postingan }\end{array}$ \\
\hline Dislikes & Subscriber & Relevan & \\
\hline Dislikes & Likes & Relevan & \\
\hline Dislikes & Dislikes & Tidak Relevan & Kedua variabel sama \\
\hline Dislikes & Viewers & Relevan & \\
\hline Dislikes & Comments & Relevan & \\
\hline Viewers & Post & Tidak Relevan & $\begin{array}{l}\text { Jumlah post tidak berpengaruh pada interaksi setiap } \\
\text { postingan }\end{array}$ \\
\hline Viewers & Subscriber & Tidak Relevan & Jumlah variabel 1 cenderung lebih besar dari variabel 2 \\
\hline Viewers & Likes & Tidak relevan & Jumlah variabel 1 cenderung lebih besar dari variabel 2 \\
\hline Viewers & Dislikes & Tidak Relevan & Jumlah variabel 1 cenderung lebih besar dari variabel 2 \\
\hline Viewers & Viewers & Tidak Relevan & Kedua variabel sama \\
\hline Viewers & Comments & Tidak Relevan & Jumlah variabel 1 cenderung lebih besar dari variabel 2 \\
\hline Comments & Post & Tidak Relevan & $\begin{array}{l}\text { Jumlah post tidak berpengaruh pada interaksi setiap } \\
\text { postingan }\end{array}$ \\
\hline Comments & Subscriber & Relevan & \\
\hline Comments & Likes & Relevan & \\
\hline Comments & Dislikes & Tidak Relevan & Jumlah variabel 1 cenderung lebih besar dari variabel 2 \\
\hline Comments & Viewers & Relevan & \\
\hline Comments & Comments & Tidak Relevan & Kedua variabel sama \\
\hline
\end{tabular}

Pada tabel 1. Perbandingan Antar Variabel Serta Analisis Relevansi Perbandingan Antar Variabel tersebut dapat dijelaskan bahwa tidak semua variabel dapat dilakukan perbandingan sehingga menjadi rasio yang relevan. Ada beberapa variabel yang tidak dapat atau tidak pantas untuk dibandingkan atau disandingkan. Setelah melakukan analisis perbandingan antar dua variabel tersebut, dapat ditemukan 10 variabel yang 
relevan dan dapat dijadikan sebuah rasio. Berikut merupakan tabel data yang relevan untuk diformulasikan menjadi rasio :

Tabel 2. 10 Data Yang Relevan Untuk Diformulasikan Menjadi Rasio

\begin{tabular}{cllll}
\hline No. & Variabel 1 & Variabel 2 & Relevansi & Rasio \\
\hline 1. & Post & Subscriber & Relevan & Post to Subscriber Ratio \\
2. & Likes & Subscriber & Relevan & Likes to Subscriber Ratio \\
3. & Likes & Viewers & Relevan & Likes to Viewers Ratio \\
4. & Dislikes & Subscriber & Relevan & Dislikes to Subscriber Ratio \\
5. & Dislikes & Likes & Relevan & Dislikes to Likes Ratio \\
6. & Dislikes & Viewers & Relevan & Dislikes to Viewers Ratio \\
7. & Dislikes & Comments & Relevan & Dislikes to Comments Ratio \\
8. & Comments & Subscriber & Relevan & Comments to Subscriber Ratio \\
9. & Comments & Likes & Relevan & Comments to Likes Ratio \\
10. & Comments & Viewers & Relevan & Comments to Viewers Ratio \\
\hline
\end{tabular}

Perincian dari setiap rasio-rasio yang ditemukan :

1. Post to Subscriber Ratio

Rasio jumlah Post terhadap jumlah Subscriber. Rasio ini menunjukan efektifitas konten yang di posting mampu menarik keinginan seseorang untuk mulai mengikuti / subscribe akun tersebut. Semakin sedikit jumlah postingan maka semakin menarik bagi publik yang akhirnya mau menjadi subscriber. Kelemahan dari rasio ini adalah data yang dihasilkan memiliki potensi atau kemungkinan tidak dapat dibandingkan dengan akun lain karena pemilik akun dapat menghapus postingannya sehingga tentu perhitungan rasio yang dihasilkan akan menjadi berubah. Karakteristik dari rasio ini adalah semakin kecil angka rasio maka semakin baik performa dari sebuah akun YouTube.

2. Likes to Subscriber Ratio

Rasio jumlah Likes terhadap jumlah Subscriber. Rasio ini menunjukan kemampuan sebuah postingan video menghasilkan likes dibandingkan dengan jumlah subscriber yang dimiliki. Likes pada postingan video tidak hanya dihasilkan dari subscriber saja, namun dapat dihasilkan dari nonsubscriber, sehingga rasio ini tidak dapat dianggap sebagai perbandingan antara likes dan subscriber secara langsung. Rasio ini menggambarkan kemampuan atau performa sebuah postingan video jika dilihat dari parameter jumlah subscriber. Karakteristik dari rasio ini adalah semakin besar angka rasio maka semakin baik performa dari sebuah akun YouTube.

3. Likes to Viewers Ratio

Rasio jumlah Likes terhadap jumlah Viewers. Rasio ini menunjukan tingkat keberhasilan sebuah postingan video untuk mengkonversi viewers menjadi likes. Semakin tinggi persentase pada rasio ini maka semakin baik performa postingan video tersebut. Karakteristik dari rasio ini adalah semakin besar angka rasio maka semakin baik performa dari sebuah akun YouTube.

4. Dislike to Subscriber Ratio

Rasio jumlah Dislikes terhadap jumlah Subscriber. Rasio ini menunjukan persentase jumlah dislikes yang dihasilkan sebuah postingan video dengan persentase jumlah subscriber yang dimiliki. Jumlah dislikes pada sebuah postingan video tidak hanya dihasilkan dari subscriber saja namun juga dapat dihasilkan dari non-subscriber secara langsung. Karakteristik dari rasio ini adalah semakin kecil angka rasio maka semakin baik performa dari sebuah akun YouTube.

5. Dislikes to Likes Ratio

Rasio jumlah Dislikes terhadap jumlah Likes. Rasio ini menunjukan persentase jumlah dislikes yang dimiliki pada postingan video dibandingkan dengan persentase jumlah likes. Jumlah likes dan dislikes sangat berpengaruh pada performa dari konten pada akun tersebut. Semakin kecil angka yang dihasilkan oleh rasio maka semakin baik performa dari akun tersebut. Karakteristik dari rasio ini semakin kecil angka rasio maka semakin baik performa dari sebuah akun YouTube.

6. Dislikes to Viewers Ratio

Rasio jumlah Dislikes terhadap jumlah Viewers. Rasio ini menunjukan persentase jumlah dislikes yang dimiliki dibandingkan dengan jumlah viewers. Semakin kecil persentase pada rasio ini maka semakin baik performa dari konten yang dibuat pada akun tersebut. Karakteristik dari rasio ini adalah semakin kecil angka rasio maka semakin baik performa dari sebuah akun YouTube. 
7. Dislikes to Comments Ratio

Rasio jumlah Dislikes terhadap jumlah Comments. Rasio ini menunjukan persentase jumlah dislikes yang dimiliki dibandingkan dengan jumlah komentar yang dihasilkan. Semakin kecil persentase pada rasio ini maka semakin baik performa dari konten yang dibuat pada akun tersebut. Karakteristik dari rasio ini adalah semakin kecil angka rasio maka semakin baik performa dari sebuah akun YouTube.

8. Comments to Subscriber Ratio

Rasio jumlah Comments terhadap jumlah Subscriber. Rasio ini menunjukan kemampuan sebuah postingan video menghasilkan komentar dibandingkan dengan jumlah subscriber yang dimiliki. Komentar pada postingan video tidak hanya dihasilkan dari subscriber saja namun dapat dihasilkan dari non-subscriber, sehingga rasio ini tidak dapat dianggap sebagai perbandingan antara komentar dan subscriber secara langsung. Rasio ini menggambarkan kemampuan atau performa sebuah postingan video jika dilihat dari parameter jumlah subscriber. Karakteristik dari rasio ini adalah semakin besar angka rasio maka semakin baik performa dari sebuah akun YouTube.

9. Comments to Likes Ratio

Rasio jumlah Comments terhadap jumlah Likes. Rasio ini menunjukan persentase komentar dibandingkan likes pada suatu postingan. Semakin tinggi rasio ini maka ketertarikan pada postingan tersebut semakin baik, sehingga konten video yang dibuat memiliki performa yang baik. Karakteristik dari rasio ini adalah semakin besar angka rasio maka semakin baik performa dari sebuah akun YouTube.

10. Comments to Viewers Ratio

Rasio jumlah Comments terhadap jumlah Viewers. Rasio ini menunjukan tingkat keberhasilan sebuah postingan video untuk mengkonversi viewers menjadi komentar. Semakin tinggi persentase maka semakin baik performa postingan video tersebut. Karakteristik dari rasio ini adalah semakin besar angka rasio maka semakin baik performa dari sebuah akun YouTube.

\section{Kesimpulan}

Penelitian ini menggunakan metode penelitian ekploratif, digunakan untuk menemukan variabel-variabel yang terdapat pada akun sosial media YouTube. Penelitian ini bertujuan untuk mencari rasio dengan menguji relevansi 6 variabel. Kredibilitas sebuah akun YouTube dapat dinilai performanya dengan rasiorasio yang ditemukan. Terdapat 10 rasio yang nantinya dapat digunakan untuk menilai, mengukur serta membandingkan kredibititas setiap akun YouTube. Implikasi dari penemuan rasio ini adalah diharapkan agar penelitian selanjutnya dapat menggunakan rasio-rasio ini untuk melakukan penelitian kuantitatif sehingga dapat melakukan perbandingan terhadap setiap akun yang ada pada sosail media YouTube.

\section{Daftar Pustaka}

[1] D. Setiawan, "Dampak Perkembangan Teknologi Informasi dan Komunikasi Terhadap Budaya," $J$. SIMBOLIKA Res. Learn. Commun. Study, vol. 4, no. 1, p. 62, 2018, doi: 10.31289/simbollika.v4i1.1474.

[2] S. Anshor, "Civic-Culture: Jurnal Ilmu Pendidikan PKn dan Sosial Budaya' Pemanfaatan Teknologi Informasi Dan Komunikasi Sebagai Media Pembelajaran,” J. Ilmu Pendidik. PKn dan Sos. Budaya, vol. 9924, pp. 88-100, 2018.

[3] G. Lingga, A. Kusuma, P. Sekolah, and T. Desain Bali, "Pemanfaatan Animasi Promosi Dalam Media Youtube," Feb. 2019. Accessed: Jan. 27, 2021. [Online]. Available: https://cashbac.com.

[4] R. F. Nanuru, "YOUTUBE: Seni Berwawasan Teknologi Modern," 2017, doi: 10.31219/osf.io/3vshc.

[5] A. Muhsin and R. Muflih, "Proses Komunikasi Siber Dalam Menyampaikan Informasi Otomotif Di Youtube Channel Otodriver," Jun. 2020. Accessed: Jan. 27, 2021. [Online]. Available: www.carreview.id,.

[6] K. D. B. Mangole, M. Himpong, and E. R. Kalesaran, "Pemanfaatan Youtube Dalam Meningkatkan Pengetahuan Masyarakat Di Desa Paslaten Kecamatan Remboken Minahasa," J. Acta Diurna, vol. 6, no. 4, pp. 1-15, 2017.

[7] B. Mudjiyanto, “Tipe Penelitian Eksploratif Komunikasi,” J. Stud. Komun. dan Media, vol. 22, no. 1, p. 65, Jun. 2018, doi: 10.31445/jskm.2018.220105.

[8] R. N. Fathiyyah and N. Rina, "Pengaruh Kredibilitas Youtuber Terhadap Sikap Penonton Pada Channel Youtube Atta Halilintar,” vol. 15, no. 2, pp. 98-118, 2019. 
[9] N. Mukaida, S. Sasaki, and T. Baba, "Id: 33," Cytokine, vol. 76, no. 1, p. 70, 2015, doi: 10.1016/j.cyto.2015.08.063.

[10] F. Masykur and F. Prasetiyowati, "Perancangan Aplikasi Rumah Pintar," SiTekin, vol. 14, no. 1, pp. 93-100, 2016.

[11] B. Hanggara, "Pengaruh Rasio Keuangan Terhadap Financial Distress Pada Perusahaan Ritel Yang Terdaftar Di Bursa Efek Indonesia,” Feb. 2020.

[12] V. Leonie and J. J. Pangaribuan, "Prediksi Video Performance Akun Youtube Buzzfeed Menggunakan Metode Naïve Bayes," vol. 5, no. April, 2020.

[13] https://www.youtube.com/user/kidrauhl, [Jan. 28, 2021].

[14] https://youtu.be/VLa39MqhUV8, [Jan. 28, 2021]. 